\title{
Study on the Teaching of Diversified English Classroom under the Idea of New Quality Education
}

\author{
Xiaofan Li \\ Zhengzhou University of Industrial Technology, Xinzheng,Henan,451150
}

Keywords: Pluralism, College, English, Classroom Teaching.

\begin{abstract}
College English classroom needs a variety of reform, only innovative teaching methods and means to achieve the purpose of college English teaching. This paper briefly analyzes the current situation of college English teaching in China and puts forward the feasible strategies of diversified English classroom teaching in colleges and universities.
\end{abstract}

\section{Introduction}

The purpose of teaching in higher education in our country is to cultivate applied talents. After entering the university, students are divided into various majors. Compared with language and English, the students pay more attention to the study of specialized courses. Therefore, the learning time of public English is less The College students in order to improve their professional quality and spend a lot of time to study professional courses, English learning can only rely on limited classroom time, so college students' English learning achievement is not ideal; coupled with the current college learning model of a student self-learning The students are still in contact with high school English, and the ideas and means of college English teaching are relatively backward, students can grasp the relevant English Keane can not meet the needs of social development. In recent years, the educators have always paid great attention to the study of college English diversified classrooms and achieved certain results. The use of a variety of college English teaching model can effectively solve the problem of college students' English learning ineffective, and cultivate more practical talents for the society.

\section{The Present Situation of English Classroom Teaching in Colleges and Universities}

The rigidity of English classroom teaching model is mainly manifested in both form and content. Among them, the form of rigid mainly refers to the teacher's teaching mode in full accordance with the traditional teaching methods, teachers unilaterally lead the classroom rhythm, with the indoctrination method for students to passively learning, and teachers and students interact or cooperation between students to learn less opportunities for learning And less, coupled with China's general, but a long time, the student's attention is difficult for up to four hours and fifty minutes to maintain a high degree of concentration, therefore, the quality of teaching teachers is difficult to guarantee. And because of the classroom form of boring, students gradually lost learning enthusiasm and motivation. The content of rigid refers to the major colleges and universities of English teaching materials are fixed and similar, the students of the textbook layout and pattern distribution has been well aware of, can not attract students; and teaching content mostly law-abiding, practical is not strong. College English learning should be more focused on practice, to enable students to apply classroom skills in life, this is the purpose of efficient education.

College English teaching orientation is not clear enough, colleges and universities should focus on cultivating English applied talents, college graduates should have a certain degree of English and ability to be able to English as a different from the high school students skills; and after a long time English training, Students can not only master the ability to use English should also enhance their language learning ability. At present, the purpose of English teaching in Chinese colleges and universities is still only to meet the various types of examinations, students are rarely the 
opportunity to practice, coupled with the evaluation mechanism of colleges and universities in most students can easily deal with, so the general recognition of college students in English learning is not Important, but can not stimulate the interest of their own learning. This is very different from the training objectives of colleges and universities, resulting in the overall level of college graduates is low, can not meet the needs of society and the times.

The interaction and participation of students refers to the influence of students on the teaching rhythm in the classroom learning, the interaction between students and mutual learning and the interaction between teachers and students, the students 'participation and interaction directly affect the students' learning effect. Good teacher-student interaction and student participation in the classroom to a large extent to improve student learning efficiency, English classroom results significantly. However, the present situation of English classroom teaching in Chinese colleges and universities is the teacher of the classroom rhythm, often according to their own teaching arrangements for classroom teaching, leaving less time for interaction between teachers and students, mutual exchange between students and mutual learning is almost difficult to occupy Effective time, which seriously weakened the students 'sense of classroom participation, leading to students' enthusiasm for learning is not strong, contrary to the main body of the university teaching principles. In addition, the interaction between teachers and students also leads to less understanding of students' learning situation and can not formulate and adjust the teaching plan suitable for students in time.

\section{The connotation of "diversification" teaching mode}

Diversified teaching model was first proposed by American education experts, and in the world caused a wave of multiple education. After years of practice, the diversified educational model is the best way to cultivate students 'learning ability and improve the quality of students' learning. China's stage of education are also trying to diversify the education attempt. Compared with the traditional education, the diversified education model refers to the diversification of the traditional teaching mode, the method, the content and the way of evaluating the students, so that the education can be flexibly adjusted according to the actual social needs and cultivate the more adaptable talents. Diversified educational model in the student's position has been a very good embodiment of the teacher as a guide to the students to guide students to take the initiative to learn and create more space and time, this education model is Quality education requires the foundation of cultivating comprehensive talents. Diversified English classroom education is the combination of the students' actual needs in real life and the teaching objectives of teachers, taking into account both theoretical and practical aspects, laying the foundation for English students in the future.

However, the diversified education has long been the embryonic form in the period of Confucius in our country. It is the typical example of diversified education, and the individualized education according to the individual characteristics and actual needs of the students is the ultimate goal of diversified education. At present, the highly efficient English classroom education is based on the actual situation of students on the educational content and objects in a timely manner to adjust the selection of students by the teaching materials, the establishment of a wide range of evaluation mechanisms, not rigidly adhere to the form of fixed teaching, Class concept, the establishment of mutual learning campus atmosphere.

\section{The implementation of diversified English teaching strategies}

First teacher orientation should be clear. The diversified English teaching model requires teachers to position their roles as guides and supervisors of students, and to make reasonable suggestions when students encounter problems. They can effectively supervise students' self-learning and give appropriate guidance in daily learning. Therefore, teachers in a wide range of English classroom teaching should be clear their own positioning, micro-classroom teaching to lay the foundation for the smooth development. A variety of college English classroom should be a combination of innovative teaching methods to serve the students in the classroom. And in 
accordance with the classroom needs to adjust the teaching methods and teaching content, to maximize the enthusiasm of students to learn. Secondly, the student's orientation should always be clear for the master of the study. Diversified college English classroom requires students as the main body of teaching, students control the rhythm of the classroom. This is very helpful to cultivate students' autonomous learning ability and initiative, and provide enough space for students to think. Moreover, a variety of English classroom will appear a variety of teaching models, students should be based on their own position to adjust their own role in time to make up for their own deficiencies. In the classroom, students are required to take the initiative to think, to protect themselves from the psychological dependence of teachers, to passive instigation for active intake, timely detection of their own learning process problems and properly resolved.

Use of network technology to promote student interaction and practice. Modern network technology provides a new tool for efficient English classroom diversification. Teachers can use online technology to teach online and interact with students online. Teachers should play the role of counseling, the use of network technology for students to facilitate the provision of personalized teaching resources, and provide teachers and students interactive platform, teachers can grasp the dynamic learning of students; student interaction platform can also meet the new needs between students. This will not only help students to develop practical ability and active learning ability, but also to promote teachers and students, students and students interaction. Online detection system can provide students with more comprehensive and reliable, more comprehensive range of performance ranking, to facilitate students to find the direction of efforts in a timely manner. In addition, the network communication technology to achieve the maximization of the efficiency of educational resources. Excellent teachers can record video, in the major colleges and universities to spread, so that more students access to excellent teaching resources. In addition, students can learn from each other through the online learning group to learn from each other and students of famous universities, and even establish a learning mutual help group with students who are ignorant and have access to a variety of campus culture and learning methods. More importantly, the online teaching model can provide students with a relatively free choice, students can choose according to their own time and interest in the content of lectures, this choice of learning methods can improve students' enthusiasm for learning and learning efficiency.

Innovative teaching ideas and teaching methods. The diversified teaching mode requires teachers and students to clarify the role of the teacher, the teacher as the guide, the student as the main body, under the guidance of this principle teachers to their own professional skills to give students adequate guidance and management at the learning level Respect for students' right to self-study. The innovation of the teaching idea is to transform the teacher-oriented into the student-centered, through the teachers to stimulate and guide, to promote students to actively create, comprehensively enhance the overall quality of self-learning ability. In the diversified college English classroom teaching, teachers should pay attention to the teaching content and the relationship between the emotional factors of students, through careful arrangements and planning, to provide students with a unique language learning experience.

In the teaching methods, it should also follow the teaching philosophy of the pace of change, in strict accordance with the diversity of students and the diversity of teaching content of teaching methods for innovative exploration and thinking. For example, teachers should create a new teaching model based on students 'autonomous cooperative learning based on the basic situation of students' subject and the actual requirements of target tasks, and stimulate the enthusiasm and motivation of college students to study English.

In addition, the innovative exploration of teaching methods is also one of the strategies of diversified English classroom teaching in colleges and universities. In the diversified and efficient English classroom, teachers should break through the traditional teaching mode teaching methods to divide each other, contact the weak limitations, using a variety of teaching methods of organic combination of ways for college English diversified classroom teaching into new vitality. For example, teachers 'lesson plans, pre-class introduction, stage testing and other teaching links can use a variety of technical means and methods to enrich the college English teaching process, to 
stimulate students' learning motivation.

Adoption of a diversified evaluation mechanism. In addition to the diversification and reform of college English classroom teaching, it is necessary to improve the diversified evaluation mechanism in addition to diversification and improvement in teaching methods and modes and contents. First of all, it should be clear that the diversification evaluation is different from the traditional classroom teaching evaluation link, the traditional evaluation refers to the teacher to the students to complete the task of one-way evaluation, the students are the evaluation results of the passive recipients. And the diversification of the evaluation mechanism to the limitations of the traditional evaluation mechanism, change teachers to the students of the one-way evaluation for the teachers and students of each other, life and life and other multi-evaluation. In a wide range of evaluation mechanism, the so-called right or wrong is only a personal point of view, there is no absolute $\mathrm{A}$ strong than $\mathrm{B}$, or absolute right or wrong.

Teachers and students will be able to learn from the evaluation of their own practical teaching level and the quality of students' learning. Students of the mutual evaluation refers to the completion of the task for students in the class students to evaluate each other, either anonymous form, it can be real name form. Life and life mutual assessment can enable students to fully understand their own tasks to complete the results in the eyes of peers is what position, it can be clear that their gap with others. In the life and life each other, the teacher to the elderly attitude to guide students mild language, objective evaluation. Finally, the purpose of the evaluation is to provide students with direction and goals, so the evaluation results do not pay too much attention, only need to participate in the evaluation process, and understand their own situation can be.

\section{Conclusion}

University is the closest to the community of the campus environment, the university's training objectives should be practical and practical. College English classroom teaching should be a comprehensive and diversified improvement, for students to enter the community, to adapt to social needs to provide skills training opportunities, so that the smooth use of English, this is the fundamental goal of college English teaching.

\section{References}

[1] Zhou Li. College English diversified teaching method research [J]. Shandong Social Sciences, 2015, (S2): 335-337. [2017-09-11]. DOI: 10.14112 / j.cnki.37- 1053 / c.2015.s2.143

[2] Tang Mingli. An Empirical Study on the Reform of Professional English Curriculum in Higher Vocational Colleges under the Diversified Assessment System - Taking Business English Listening and Speaking as an Example [J]. English, 2015, (05): 103-104 + 114. [2017-09-11].

[3] Chen Jun, Sun Jianguang.Application of Diversification Evaluation System in College English Teaching [J]. Journal of Liaoning Technical University (Social Science Edition), 2014,16 (03): 323-326. [2017-09- 11].

[4] Liu Wenjie. A model of cultivating diversified teaching skill of English normal students [J].Journal of Leshan Teachers College, 2013,28 (07): 130-132 + 136. [2017-09-11].

[5] Sun Zhengyan. Integrating pluralistic English news in college English teaching [J]. Chinese Journal of Foreign Languages Education, 2012, (09): 157-158. [2017-09-11]. 